\title{
PRIMARY SARCOMA OF PULMONARY ARTERY AND VALVE: MULTIMODALITY TREATMENT BY CHEMOTHERAPY AND HOMOGRAFT REPLACEMENT
}

\author{
Hans-Reinhard Zerkowski, MD, ${ }^{\mathrm{a}}$ Hans-Stefan Hofmann, MD, ${ }^{\mathrm{a}}$ Iwan Gybels, MD, and Jürgen Knolle, MD, \\ Halle, Germany
}

Primary pulmonary sarcomas are extremely rare tumors. Since the first description by Mandelstamm ${ }^{1}$ in 1923 , only about 100 case reports have been published, and only a few have dealt with combined treatment of primary sarcoma. We report on a woman with a metastasizing pulmonary sarcoma of the pulmonary valve with infiltration of the pulmonary artery. After complete remission of the pulmonary metastases with polychemotherapy, the patient underwent curative resection of the tumor and insertion of a cryopreserved homograft.

A 49-year-old woman was admitted because of increasing short of breath with exercise. She had pericarditis about 6 months previously. Since then, both chest and back pain occurred frequently, associated with tachycardia and dyspnea. Auscultation revealed a $3 / 6$ systolic ejection murmur in the second left intercostal space and a markedly split second heart sound. There were signs of right ventricular overload on the electrocardiogram. The initial chest radiograph showed several bilateral pulmonary nodular lesions, confirmed by computed tomographic scan. Two-dimensional and transesophageal echocardiography revealed an enlarged right ventricle and an abnormal structure in the main and right pulmonary arteries. Right heart catheterization showed elevated right ventricular and pulmonary arterial pressures, with a ventricular-distal pulmonary artery gradient of $40 \mathrm{mmHg}$. The main and right pulmonary arteries were seen by cineangiography to be incompletely perfused. Needle biopsy was carried out for cytologic and histologic examination of the pulmonary nodular lesions, which we had suspected and later confirmed to be hemangiosarcoma. Elective resection of the right sided lung metastases was incomplete as a result of life-threatening hemodynamic instability. Histologic examination of one of these tumors revealed granulation and scar tissue without evidence of malignancy.

Because of progression of right heart failure and growth of the pulmonary lesions seen on the computed tomographic scan, chemotherapy was initiated. In the subsequent 7 months, polychemotherapy (etoposide, vincristine, ifosfamide, adriamycin) was administered for six

From the Department of Cardiothoracic Surgery and Institute of Pathology, ${ }^{\text {b }}$ Martin-Luther-University Halle-Wittenberg, Halle, Germany.

Received for publication Nov. 7, 1995; accepted for publication Feb. 2, 1996.

J Thorac Cardiovase Surg 1996;112:1122-4

Copyright (c) 1996 by Mosby-Year Book, Inc.

$0022-5223 / 96 \$ 5.00+0 \quad \mathbf{1 2 / 5 4 / 7 2 5 6 3}$

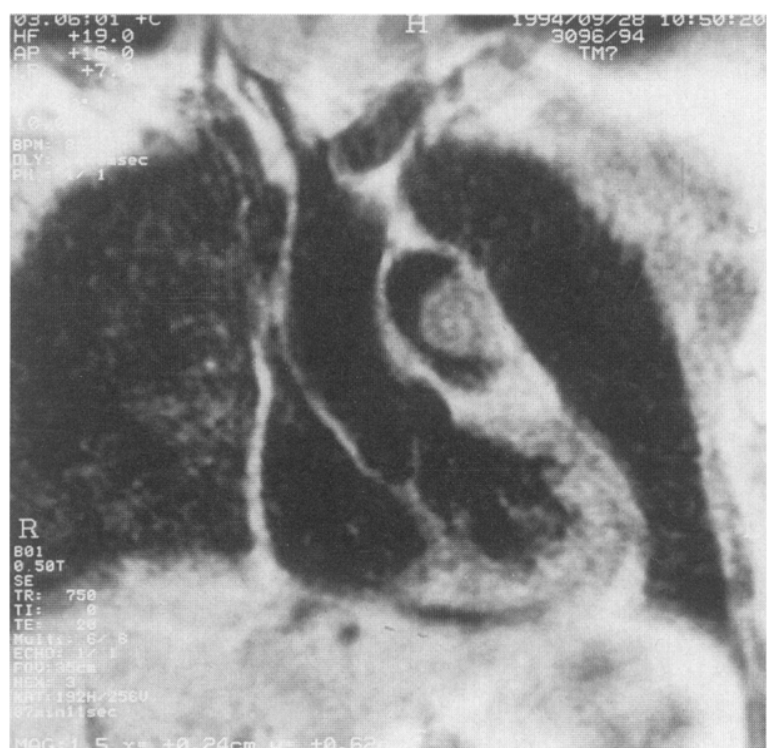

Fig. 1. Preoperative magnetic resonance scan shows a mass in the pulmonary artery.

cycles. Response was demonstrated after the second cycle. At the end of this treatment, magnetic resonance imaging revealed complete remission of all pulmonary nodules and reperfusion of both lungs; significant tumor remained in the right ventricular outflow tract and the pulmonary arteries (Fig. 1).

Five months after chemotherapy, with cardiopulmonary bypass and hypothermia $\left(28^{\circ} \mathrm{C}\right)$, complete resection of the tumor was performed. The tumor almost completely blocked the lumen of the pulmonary artery and invaded into the anterior wall of the pulmonary artery. In addition, the tumor originated from the pulmonary valve proximally, could not be separated from the anulus, and extended distally into both pulmonary arteries. The pulmonary artery was resected beyond the bifurcation, including the valve and parts of the anterior right ventricular outflow tract, and replaced with a cryopreserved valved bifurcation homograft (Bioimplant Services Foundation, Eurotransplant, Leiden, The Netherlands). The prosthetic valve was placed proximally in the previous plane of the pulmonary valve. The partially resected outflow tract of the ventricle was reconstructed with autologous pericardium. Tumor extending into the arteries was resected as in a pulmonary thromboendarterectomy. His- 
Table I. Review of patients treated surgically in the past 10 years

\begin{tabular}{|c|c|c|c|c|}
\hline Authors, year & Location & Metastases & Therapy & $\begin{array}{c}\text { Status and (months between } \\
\text { therapy and status) }\end{array}$ \\
\hline de Smet et al. ${ }^{8} 1986$ & PA & No & Resection & Dead, 0 \\
\hline Krüger et al., ${ }^{2} 1990^{1}$ & PA & Lung & Resection & Dead, 7 \\
\hline Nehrlich et al., 91990 & PA & Lung, adrenal glands & Resection & Dead, 2 \\
\hline \multirow[t]{2}{*}{ Iversen et al. ${ }^{4} 1991^{3}$} & $\mathrm{PA}$ & No & $\begin{array}{l}\text { Resection, chemotherapy, } \\
\text { radiation }\end{array}$ & Dead, 18 \\
\hline & PA & No & Resection & Alive, 3 \\
\hline Head et al., ${ }^{5} 1992$ & $\mathrm{PA}$ & No & $\begin{array}{l}\text { Resection, chemotherapy, } \\
\text { radiation }\end{array}$ & Alive, 36 \\
\hline Berney et al., ${ }^{10} 1992$ & PV & No & Resection & Alive, 11 \\
\hline Johansson et al., ${ }^{11} 1994$ & PA & Mediastinum & Resection & Died at operation \\
\hline Tanaka et al., ${ }^{3} 1994$ & PA & Lung & Resection & Dead, 8 \\
\hline Kawamura et al., ${ }^{12} 1994$ & PA & Lung & Resection & Dead, 10 \\
\hline Current case report, 1996 & PA & Lung & $\begin{array}{l}\text { Neoadjuvant chemother- } \\
\text { apy, resection }\end{array}$ & Alive, 20 \\
\hline
\end{tabular}

$P A$, Pulmonary artery; $P V$, pulmonary vein.

tologic examination of the resected specimen showed no viable tumor tissue. After 17 days, the patient was discharged and was feeling well. At follow-up examination 12 months after the operation, the patient was alive and well without any evidence of recurrence.

Favorable prognosis of primary pulmonary sarcoma depends on early diagnosis. The symptoms are nonspecific; the cause for admission is often a suspicion of a pulmonary embolism. Sixty percent ${ }^{2}$ of pulmonary sarcomas are diagnosed at postmortem examination, but this is happening with decreasing frequency as a result of newer therapy in the past decade. Currently, surgical resection remains the therapy of choice (Table I). The vast majority of the patients in reported cases (70\%) were operated upon with the presumed diagnosis of thromboembolism. Simple resection of the tumor without prosthesis or graft substitution is the most frequent operation performed. Resection is often incomplete (ratio $1: 2$ ) because of the advanced stage of the tumor. Only a few cases of alloplastic ${ }^{3,4}$ or homograft ${ }^{5,6}$ replacement have been reported. Precise preoperative planning with echographic measurements of the pulmonary valve, pulmonary artery, and branch pulmonary arteries is desirable when doing elective replacement.

Adjuvant radiotherapy, chemotherapy, or a combination of both ${ }^{4,5}$ have so far been carried out only after tumor resection. To our knowledge, multimodal treatment with chemotherapy as pretreatment before operation, such as was used in our case, has not been reported. The prognosis is extremely poor. Only $10 \%$ of the patients survive longer than 1 year after diagnosis. ${ }^{7}$ The mean survival of patients with primary resection (10 months) is significantly longer than that of patients without resection. ${ }^{2}$ Adjuvant radiotherapy, chemotherapy, and combinations are not regarded as effective by some despite significantly longer survival ${ }^{2}$ because survival after the third postoperative year is similar to that of patients who have not received adjuvant treatment.
Table I, however, shows that patients who undergo combined therapy ${ }^{4,5}$ appear to have the longest survival. When multiple metastases are present, as in our case, chemotherapy after complete or partial remission may allow resection. ${ }^{6}$

These data suggest that after a chemotherapeutic response extensive resection and reconstructive surgery is justified in patients with pulmonary sarcoma.

\section{REFERENCES}

1. Mandelstamm M. Über primäre Neubildungen des Herzens. Virchows Arch (Pathol Anat) 1923;245:43-57.

2. Krüger I, Borowski A, Horst M, de Vivie ER, Theissen $P$, Gross-Fengels W. Symptoms, diagnosis, and therapy of primary sarcomas of the pulmonary artery. Thorac Cardiovasc Surg 1990;38:91-5.

3. Tanaka I, Masuda R, Inoue M, et al. Report of a case with complete resection and graft replacement, and review of 47 surgically treated cases reported in the literature. Thorac Cardiovasc Surg 1994;42:64-8.

4. Iversen S, Hake U, Schmiedt W, Jakob H, Ramp U, Gabbert $\mathrm{H}$, et al. Resection of central primary pulmonary sarcoma. Eur J Cardiothorac Surg 1991;5:603-7.

5. Head HD, Flam MS, John MJ, Lipnik SS, Slater DL, Stewart RD. Long-term palliation of pulmonary artery sarcoma by radical excision and adjuvant therapy. Ann Thorac Surg 1992;53:332-4.

6. Anderson MB, Kriett JM, Kapelanski DP, Tarazi R, Jamieson SW. Primary pulmonary artery sarcoma: a report of six cases. Ann Thorac Surg 1995;59:1478-90.

7. Bleisch VR, Kraus FT. Polyploid sarcoma of the pulmonary trunk. Cancer 1980;46:314-24.

8. Smet de JM, Dieudonne P, Contu E, Le Clerk JL, Goffin Y, Boelpape de C. Pulmonary artery leiomyosarcoma treated surgically. Thorac Cardiovasc Surg 1986:34:98-9.

9. Nehrlich A, Permanetter W, Ludwig B, Remberger K. Pri- 
mary leiomyosarcoma of the truncus pulmonalis. Path Res Pract 1990;186:296-9.

10. Berney CR, Roche B, Kurt AM, Spiliopoulos A, Megevand $\mathrm{R}$. Leiomyosarcoma of the pulmonary hilar vessels. Thorac Cardiovasc Surg 1992;40:48-51.

11. Johansson L, Carlen B. Sarcoma of the pulmonary artery: report of four cases with electron microscopic and immunhistochemical examinations, and review of the literature. Virchows Arch 1994;424:217-24.

12. Kawamura M, Takahasi Y, Sakata $Y$, et al. A case of malignant fibrous histiocytoma of the pulmonary artery. Nippon Kyobu Geka Gakkai Zasshi 1994;42:456-60.

\section{SALVAGE RESECTION OF A CHEMOREFRACTORY MEDIASTINAL GERM CELL TUMOR}

Michel Rivoire, MD, PhD, ${ }^{a}$ Eric Voiglio, MD, ${ }^{a}$ Pierre Kaemmerlen, MD, ${ }^{b}$ Isabelle Treilleux, MD, ${ }^{c}$ Pierre Biron, MD, ${ }^{d}$ and Jean Pierre Droz, MD, ${ }^{\mathrm{d}}$ Lyon, France

Primary mediastinal nonseminomatous germ cell tumors are uncommon, accounting for only $1 \%$ to $3.5 \%$ of all tumors of the mediastinum and $1 \%$ to $2 \%$ of all germ cell tumors in male patients. ${ }^{1}$ Outcome for these tumors has improved considerably with the combination of cisplatin-based chemotherapy followed by aggressive operation. $^{2}$ Nevertheless, $50 \%$ to $60 \%$ of cases are not cured by this multimodal approach; almost all patients who have only partial response status without return to normal serum levels of tumor marker and those who have relapses

From the Departments of Surgery, ${ }^{\mathrm{a}}$ Radiology, ${ }^{\mathrm{b}}$ Pathology, ${ }^{\mathrm{c}}$ and Medecine, ${ }^{\mathrm{d}}$ Léon Bérard Cancer Center, Lyon, France.

Received for publication March 19, 1996; accepted for publication March 26, 1996.

J Thorac Cardiovasc Surg 1996;112:1124-6

Copyright (C) 1996 by Mosby-Year Book, Inc.

$0022-5223 / 96 \$ 5.00+0 \quad \mathbf{1 2 / 5 4 / 7 3 7 8 7}$ with elevated levels of tumor marker die, even when treated with high-dose chemotherapy and hematopoietic stem-cell support. Salvage resection of chemorefractory germ cell tumors of the testis was recently reported to result in a cure rate of $50 \%$ in one patient population. ${ }^{3}$ Salvage resection of mediastinal germ cell tumors has not yet been reported. We describe the case of a patient with a chemorefractory primary mediastinal germ cell tumor in whom a series of operations resulted in sustained, complete remission.

A 30-year-old man was referred to our hospital in February 1992 for a histologically confirmed pure primary choriocarcinoma of the anterosuperior mediastinum with widespread lung metastases (Fig. 1). Ultrasonography showed both testes to be normal. No other metastatic sites were detected with whole-body computed tomographic scan. The initial serum level of human chorionic gonadotrophin hormone (hCG) was $80,000 \mathrm{mIU} / \mathrm{ml}$ (normal $<4$

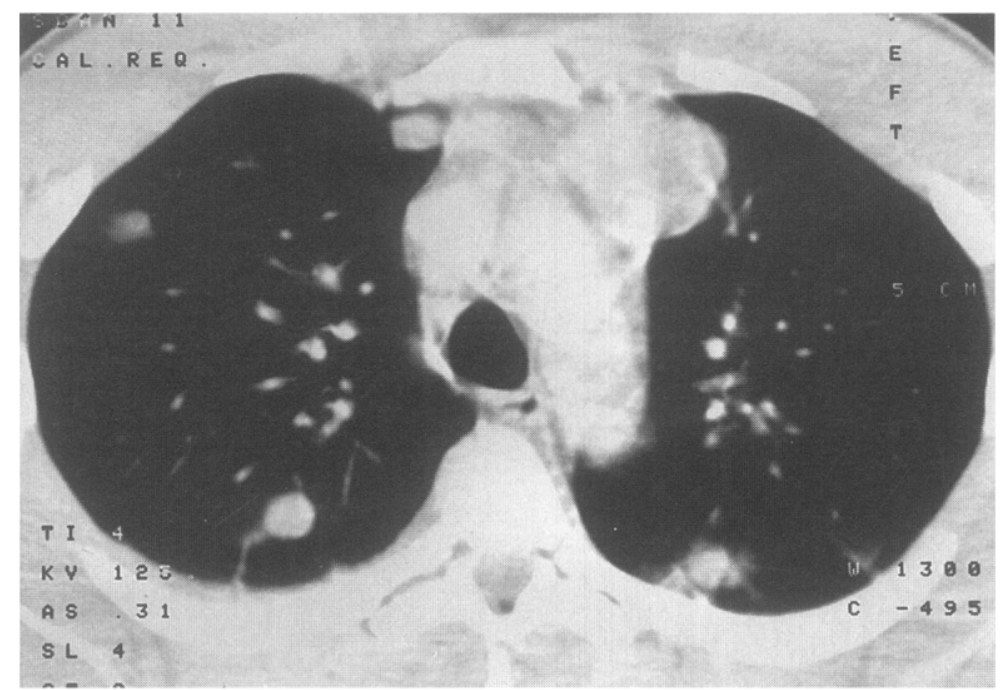

Fig. 1. Chest computed tomographic scan showing tumor of anterosuperior mediastinum with bilateral lung metastases. 